\title{
Bilgi sarmalı çerçevesinde süreçlerin karşılıklı etkileşimi üzerine bir araştırma
}

\author{
Research on the mutual interaction of the processes within the \\ framework of the knowledge spiral
}

Arif Orçun Sakarya ${ }^{1}$

Öz

${ }^{1}$ Dr. Öğr. Üyesi, Çankaya Üniversitesi, Ankara, Türkiye, sakarya@cankaya.edu.tr

ORCID: 0000-0003-0715-7791

Başvuru/Submitted: 10/10/2021

Revizyon/Revised: 2/12/2021

Kabul/Accepted: 15/12/2021

Yayın/Online Published: 25/12/2021

Atıf/Citation: Sakarya, A.O., Bilgi sarmalı çerçevesinde süreçlerin karşılıklı etkileşimi üzerine bir araștırma, bmij (2021) 9 (4):

1564-1581, doi:

https://doi.org/10.15295/bmij.v9i4.1956
Günümüzde bilgi yönetimi işletmelerin rekabet güçlerinin artırılması yönünde odaklanılan konulardan biridir. Özellikle dinamik çevre ile etkileşim sırasında bilginin şekillenmesi noktasında, bilginin dönüşümü ve kullanılma amacı da işletme performansına etki edebilecek olgular olarak ortaya çıkmaktadır. Buna bağlı olarak, çalışmanın amacı, mikro ölçekli işletmelerde sarmal bazlı bilgi yönetimi ve yaratılması için uygun şartların oluşup oluşmadığının ölçülmesidir. İlgili literatür ve bilgi yönetimine farklı yaklaşımların incelenmesini takiben, çalışmanın araştırma bölümünde ise bir üniversitenin kuluçka merkezi bünyesinde bulunan ve bilgi yoğun ürün veya hizmet üreten mikro ölçekli işletmelerin ile yapılan görüşmelerin sonuçları tartışılmıştır. Buna göre, işletmenin dahilinde bilginin yaratılması için gerekli şartları büyük ölçüde sağladıkları sonucuna ulaşılmıştır. Bu bağlamda özellikle ortak karar alma mekanizması, proje bazlı çalışma, inovasyon, birden fazla işte yetkinleşme ve bilgiye erişim olgularının ön plana çıktığı görülmüştür. Bunlara ek olarak da özellikle bilginin dönüştürülmesi çerçevesinde piyasa odaklı yaklaşımların da şirketlerin gündeminde olduğu gözlemlenmiştir.

Anahtar Kelimeler: Bilgi Yönetimi, Sarmal, Uygulanabilirlik

Jel Kodlari: D83, M19

\begin{abstract}
At present, knowledge management is one of the topics focused on increasing firm competitiveness. However, significantly when knowledge is shaped during interaction with the external environment, the transformation and usage of knowledge emerge as the notions that may affect firm performance. Accordingly, the study aims to measure the favorable conditions for spiral-based knowledge management and knowledge creation in micro-sized enterprises. Following the related literature and the examination of the different approaches to knowledge management, in the research part of the study, it has been discussed the interview results made with the micro-sized firms which operate within the incubator center of a university and produce knowledge-intensive products or services. Accordingly, it has been deduced that the required conditions are mostly satisfied for the knowledge to be created. In this context, notions including joint decision-making mechanism, project-based work, innovation, and competence on more than one job and access to information are highlighted. Additionally, market-oriented approaches are in firms' agenda in knowledge conversion.
\end{abstract}

Keywords: Knowledge Management, Spiral, Applicability

Jel Codes: D83, M19 


\section{Extended Abstract}

\section{Research on the mutual interaction of the processes within the framework of the knowledge spiral}

\section{Literature}

The purpose of the study is the measure the favorable conditions necessary to create knowledge-based on Nonaka and Takeuchi's knowledge spiral model. In terms of this framework, researchers have stated how knowledge is created and converted in their models. In the related literature, knowledge conversion and the dynamic knowledge spiral processes have been used to investigate the basis of a firm's innovation processes, project management, and learning systems in general, and the approaches to education that mainly underline the dynamic nature of knowledge creation. In addition to these, different sectoral policies including banking, mining, construction and tourism can be observed by the same token. Regarding the firm's characteristics, although studies about entrepreneurship and family enterprises can be followed, few researchers have mentioned the context of technology-intensive micro-enterprises within an incubator setting. However, as it can be assumed in terms of the intensity of the intensive ecosystem regarding research and development in the incubator environment, the study's findings underline at which points knowledge can be created within the organizational culture regarding the environment in which the sample firms operate. Accordingly, this study contributes to the literature by taking the dynamic knowledge-intensive nature of the firm, along with the sectoral characteristics in which it operates, to observe the implementation of the model in terms of work and management practices.

\section{Design and method}

This study takes the form of applied research and aims to explore the presence of the knowledge spiral in micro-sized firms within the incubator center of a university. At this stage, as the firms involved are mainly operating in the knowledge-intensive sectors, the management of knowledge in the production or the service processes is expected to increase a firm's competitiveness. Therefore, to measure the firm's intentions about applying the spiral-based approach, in-depth interviews are conducted with the firms' managers since it is assumed that they have the ultimate ability to create a favorable in-house environment to satisfy the required conditions. The framework of the interviews is based on Nonaka and Takeuchi's five different dimensions, with 13 subdimensions being identified to complete the set of requirements set within a firm. The coding technique was then applied to determine the frequency of the focal points mentioned in the interviews.

\section{Findings and discussion}

Regarding the findings, the managers interviewed mostly emphasized the dynamic nature of the knowledge involved in the context of market interaction. It has also been deduced that the sample firms are well motivated to acquire new knowledge and provide the continuum of interaction with the external environment. In order to do that, they aim to encourage teamwork and work specialization on different topics for the firm to benefit from the ecosystem in which it operates. One of the interesting findings is about the firm's motivation in terms of the decision-making processes, in that the managers mostly prefer to implement a participative decision-making style. In this framework, the findings indicate the dynamic nature of the firms involved and the knowledge-intensive processes that generally lead to an organic structure.

\section{Results, suggestions and limitations}

The study results indicate that incubator firms are generally motivated to create a favorable environment to implement spiralbased knowledge creation processes within the organization. Here, areas including innovation, customer relations, process improvement related operations, and related projects aimed at providing knowledge creation, are the ones that the managers primarily identify. In order to do this, tools such as knowledge intake, decision-making processes and work rotations are used by the firms. However, various constraints that affect interaction exist regarding the study's limitations. In particular, this is true of firm-based regulations due to the small scale and the number of firms in the sample. Accordingly, a research study should be conducted involving larger incubators to achieve more inclusive results. 


\section{Giriş}

Rekabetin ve küreselleşmenin arttığı iş dünyasında işletmeler farklı uygulamalara yönelmektedirler. Özellikle, piyasaya yeni ve yenilikçi özellikler taşıyan ürünlerin rakiplerden daha hızlı sunulabilmesi için gereken üretim teknolojisine ulaşılması, iş süreçlerinin optimize edilmesi gibi noktalar büyük rekabet ortamlarından bazılarını oluşturmaktadırlar. Buna ek olarak satış ve pazarlama imkânlarının artırılarak müşteri portföyünün geliştirilmesi yönünde müşteri ilişkilerinin iyileştirilmesi de işletmelerin ayrı bir rekabet alanını oluşturmaktadır

Bunlara ek olarak bilgi teknolojilerinin (BT) işletmelerde yoğun bir şekilde kullanılması da yukarıda sayılan rekabet ortamlarında tutunabilmek için işletmelerce sıkça tercih edilmektedir. BT desteği ile işletmeler sadece uygulamalar süresince değil aynı zamanda yönetsel süreçlerde de pozitif sonuçlar doğurmaktadır. Yukarıdaki olgular dikkate alınarak; biraz sonra alternatif bir şekilde tanımlanacak olan bilgi yönetimi (BY) uygulamalarının işletmeler için düşük maliyet sağladığı, kar marjlarını genişlettiği, işletme değerini ve piyasa payını artırdığı gözlemlenmiştir. Aynı zamanda işletme içerisindeki fikirlerin daha iyi yönetimi, çalışanların işletmeye bağlllıkları ve güçlendirilmesi ile memnuniyetlerinde de BY uygulamaları olumlu sonuçlar verebilmektedir. Bu gelişmelerin işletmeye katkı sağlaması için işletmede BY kültürünün yayılması ve içselleştirilmesi de önem kazanmaktadır. Buna bağlı olarak BY uygulamalarına geçmek isteyen işletmelerin; işletme içerisinde BY kültürünün gelişebilmesi için de uygun ortamı hazırlamaları gerekmektedir. Buna bağlı olarak çalışmada Nonaka ve Takeuchi' nin BY sarmalı çerçevesinde şirketlerde BY uygulamalarına imkân verecek ortam oluşumu sorgulanmıştır.

\section{Literatür taraması}

\section{Veri, bilgi ve üst bilginin farkı}

Çalışmanın amacına paralel bir tanıma göre BY mevcut ve gereken bilginin belirlenmesi ve örgütsel amaçlara ulaşma yönünde bilgi sermayelerinin geliştirilmesi için planlama yapılarak faaliyetlerin kontrol edilmesidir (Gunasekaran ve Ngai, 2007:2392).

BY literatüründe en çok değinilen konulardan biri de "veri" (data) "enformasyon" (information) ve "bilgi" (knowledge) arasındaki farktır. Veri genellikle esaslar, gözlemler ve mesajları içermektedir, düzenli değildir, bağlam ya da örüntüden bağımsız olarak enformasyon üretilmesi için kullanılmaktadır. Özellikle derinlemesine bilgi üretiminde kullanılması durumunda ham halde bulunduğu da düşünülebilir. Enformasyon ise verinin kategorize edilmiş, hesaplanmış ve insanlar tarafından daha kullanılabilir bir hale getirilmiş bir türüdür, yani bir amacı ve anlamı olan ve "büyük resmi gösteren" veridir. Örneğin bir şirkette BT, verinin enformasyon haline getirilmesi için kullanışlı olabilir. Bilgi ise enformasyonun işlenmesi sonucunda ortaya çıan bir olgudur. Bir başka açıdan anlama ve anladığını yapma ile bağlantılı iken insanların edindiği tecrübe de bilgi tanımına dahildir; veriler sayesinde insan beyninin ne yaptığının da bir göstergesi konumunda olduğu da varsayılabilir. Yapısal veri tabanından kesintisiz bilgi aktarımını hedefler. Bilgi ise yapısal veri tabanı ve kimi yapısal olmayan belgelerden yararlanırken bunların yeniden sunulmasını ve kullanılmasını sağlar. Bu şekilde karar süreçlerine destek de sağlanmaktadır. Bilgi de yine aynı yolu izleyerek işletme prosedürlerini yönetmektedir.

Veri ve bilginin zamana bağlı olan farklarının da olduğu düşünülebilir. Zaman içerisinde insan beyninde veri alındığı şekliyle saklanırken, bilginin formatı farklılaşabilir. Ayrıca, çalışmanın kapsamında da bulunan bilgininin iletişim yolu ile değiştirilmesi, çoğaltılması ve azaltılması sonucunda dinamik bir yapıya da sahip olduğu söylenebilir. Buna karşın veriler genellikle bir durumun değerlendirilmesi ve çözülmesi için kullanıldıkları için daha çok statik olarak nitelendirilebilirler. Kısaca, veri/bilgi ilişkisinde veriler girdiler, insan beyni süreci yöneten bir merkez, bilgi ise çıtı olarak düşünülebilir. Buna bağlı olarak da kaliteli bilgi üretimi için kaliteli veri girişi sağlanması; verilerin kaliteli bir süreçten geçirilmesi için de yüksek bir entelektüel seviyeye sahip olunması gereklidir.

\section{İşletmelerde bilgi yönetimi ortamı ve araçları}

Günümüzde işletmelerin (Aiai, 2021) içerisinde bulundukları çevreye kısaca bakıldığında;

- Piyasa rekabetinin arttığı ve inovasyon (yenilik) oranının yükseldiği,

- İşten çıkarmaların biraz sonra değinilecek olan gayri resmi bilginin daha resmi metotlar ile değiştirilmesini zorunlu kıldığı,

- Rekabetçi baskının değerli bilgiye sahip işgücünü azalttığı,

- Bilgiye ulaşma ve tecrübe etme için gereken zamanın düştüğü, 
- Erken emekliliğin ve artan işgücü hareketliliğinin işgücünün bilgisini azalttığı̆,

- Stratejik yönün değişmesi sonucunda belirli bir konudaki bilgiyi eksilttiği görülmektedir.

$\mathrm{Bu}$ ve buna benzer faktörler ve amaçlara bağlı olarak günümüzde BY çeşitli sürükleyiciler ile şekillenirken işletmelerin işleri de daha fazla bilgi yoğun olmakta ve rekabet ekseni de daha fazla bilgiye kaymaktadır. Bu sürükleyiciler, yoğun rekabet ortamının yanı sıra bu ortam içerisinde faaliyet gösteren işletmeleri yönlendiren iç çevreye bağlı değişkenlerdir. Bu değişkenler; stratejik açıdan bakıldığında değişim kültürü ve bu kültür içerisinde şirket içerisinde artan iletişim ve birimler arası iş birliği, iletişimin artması gibi konuları hedeflerler. Bu yönde; BT destekli portalların yayılması, üretim, finansman ve pazarlama alanlarında daha kaliteli hizmet verilebilmesi için öğrenen işletmeler kavramının gelişmesi ve tüm bunların etkin olarak gerçekleştirilebilmesi için süregelen uygulamalar olarak sayılabilir. Bu uygulamalar; veri ambarı, veri madenciliği, içerik yönetimi, doküman yönetimi gibi kavramların yanı sıra ilgili uygulamaların sürdürülebilmesi için kurulan altyapılardır. Bu altyapılar da genel olarak şirketin teknolojik mimarisi ile yakından ilgilidir. Bir başka açıdan yaklaşıldığında ise aslında bir şirket içerisindeki bilgi altyapısını oluşturan 3 öğe (Intezari, Taskin ve Pauleen, 2017:494) tarafından bilgi süreçleri, bilgi kültürü ve bilgi teknolojileri olarak sıralanmıştır.

Yukarıda sayılan olgular aynı zamanda BY ile entegre bir şekilde yürütülebilir. İşletme içi ortam dikkate alındığında ise BY uygulamaları sırasında entelektüel sermayenin de ilgili uygulamalar üzerinde büyük bir etkisi bulunduğu görülmektedir. Bir açıdan bakıldığında BY sayesinde işletmeler entelektüel sermayelerinden fayda sağlamaktadırlar. BY uygulamalarında önemli bir yere sahip olan "entelektüel sermaye" (entelektüel varlık) kavramı daha detaylı olarak incelendiğinde aşağıdaki sınıflandırma ile karşılaşılmaktadır (OECD, 2021)

1-İnsan sermayesi: İnsan sermayesi; bir işletme içerisinde, kişilerin bilgi ve becerilerine verilen isimdir. Bu sermaye, onları taşıyan çalışan ve yöneticilerde bulunur. Bir işletmede BY sistemi bulunmaması durumunda işten eve dönen kişiler bu sermaye ve dolayısıyla bilgilerini de yanlarında götürebilirler;

2-iliş̦kisel sermaye: Bir firmanın müşteri, tedarikçi ve araştırma-geliştirme (Ar-Ge) ortakları gibi dış paydaşlarla olan ilişkilerinde doğan kaynaklar ile ilgili sermaye türüdür. Müşterilerin satış/pazarlama çalışanları başta olmak üzere çalışanlar ile aralarında bir bağ kurulduğu gerçeği göz önüne alınırsa, bu sermayenin de çalışanlar tarafından elde tutulduğu söylenebilir. Dolayısıyla, işveren ve çalışanlar tarafından elde tutulan müşteri sermayesi aynı zamanda işletmeye müşteri bağlılı̆̆ının da bir göstergesi olarak düşünülebilir.

3-Yapısal sermaye: Onları yaratan yönetici ve çalışanlardan bağımsız rutinler, prosedürler, olan sistemler, kültürler ve veri tabanları gibi olgulardan oluşan sermayeye denir.

Entelektüel sermayeye ek olarak günümüzde işletme amaçlarına ulaşılabilmek için çalışanların bilgileri, ürün, süreç, rakipler ve müşteriler hakkında veri ve enformasyon ile patent gibi fikri mülkiyet haklarından oluşan "bilgi sermayesi" kavramı da ön plana çıkmaktadır (Gartner, 2021). Aynı bağlamda (Nonaka vd., akt. Baskerville ve Dullpovici, 2006)'ya göre "bilgi varlıkları" ise, firma özelinde firmaya değer yaratan kaynaklar olarak tanımlanmaktadır. Sermayeler arasında oluşan bu farklıklar bazında BY çerçevesinde kullanılan bilgi türleri arasındaki ayrımın altının çizilmesi gerekmektedir. Bu ayrımın yapılması bir yandan farklı tür bilgiler için kullanılan uygulamaların daha iyi belirlenmesini; bir yandan da bu uygulamaların işletme amaçlarına ulaşılması sırasında ne yönde kullanılabileceklerinin daha iyi anlaşılmasını sağlayacaktır. BY çerçevesinde iki tür farklı bilginden söz edilebilir. Bunlardan birincisi dışsal (açık) bilgi; ikincisi ise içsel (zımni/örtülü) bilgi olarak nitelendirilen bilgi türüdür. Dışsal bilgiler resmi bir dilde ifade edilebilen ve şirket geneline yayılabilen bilgi olarak açıklanabilir. Dışsal bilgi resmi ve sistematik bir dille ifade edilebilen ve veri, bilimsel formül, özellikler ve buna benzer olan bilgiler olarak da tanımlanmıştır (Nonaka, Toyama ve Konno, 2000). Örtülü bilgi (gayri resmi bilgi) ise, kişilerin beyinlerinde olan ve kolay bir şekilde ifade edilemeyen bilgilerdir (Grover ve Davenport, 2001) Bunlara örnek olarak öğrenme ve know-how (teknik bilgi), sayılabilir. (Polanyi, akt. Rai, 2011:781)'e göre de örtülü bilgi, sübjektif, tecrübe bazlı ve çalışma, cümleler ve formüller ile ifade edilemeyen bilgi türüdür. Dışsal bilgiler kurumun misyonuna ulaşmasını kolaylaştırması ve şirketin rekabet ortamında hayatta kalması için alınacak stratejik kararlar sürecinde önemli bir araç olarak genel çerçeveyi çizerken, içsel bilgiler yazılı prosedürler ve kişisel becerilerle arasında doğrudan bağlantı kurulması aşamasında daha etkindir. Her iki bilgi türü için de bilgi faktörünün stratejiler, politikalar ve iş tanımlarına yazılı olarak yansıtılması ve geliştirilen politikalarda kurumda bilgi artırımının ön plana alınması önemli bir rol oynamaktadır.

Bütünsel bir yaklaşımla; BY'nin iki temel noktası ile bir iş aktivitesi olarak düşünülmesi söz konusu olabilir. 
1-İşletme stratejisinin ve politikalarının tasarımı sırasında bilginin rolünün dikkate alınarak bu tutumun işletmenin tüm seviyelerinde uygulanması,

2-İşletmenin entelektüel aktifleri arasındaki ilişkilerin belirlenerek bunların olumlu sonuçlar düzenlenecek şekilde kullanılması

BY sırasında, bu faaliyetler teknoloji, işletme yapısı ve kişilerin entelektüel yeteneklerinin birleştirilerek oluşturulması amaçlanır. Buna bağlı olarak BY; işletme dahilinde öğrenme, problem çözme ve karar verme aşamalarında kullanılabilir. Yukarıda da belirtildiği gibi BT entegrasyonun etkin olarak sağlanması ile BY uygulamaları BY uygulamaları daha sistematik hale getirilebilir. Burada “entegrasyon" kavramının odağında (Becerra-Fernandez ve Sabherwal, 2001)'a göre, örgütsel rutinler, idare ve içsel-dışsal bilgi paylaşımı gerektiren süreçler bulunmaktadır. BT destekli BY uygulamalarının yararlarından birinin işletmede yenilikçiliğin, verimliliğin artırılması ve çalışanlar arasındaki iletişimin yoğunlaştırılması olduğu göz önüne alındığında, teknolojinin tek başına BY uygulamalarını daha tekin hale getirdiği düşünülmeyebilir. Özellikle bilgi yaratılması sırasında verilerin yargılar ve tecrübeler ile de birleştirilmesi gerekmektedir. Bu aşamada şirket çalışanlarının entelektüel seviyelerinin ve sosyal ilişkilerinin de BY uygulamaları sırasındaki önemi anlaşılabilmektedir. Bu bağlamda (Johannessen, 2008:404)'ün de altını çizdiği gibi “bir firmanın yetenekleri temelde firmanın içerisindeki sosyal ilişkilerde bulunan sosyal norm ve değerler bazında gelişmektedir. Bu şirketin bilgiyi nasıl geliştirip bütünleştirdiğini etkiler ve sonunda şirketi inovatifbir yola çevirir. Bu esaslar da şirketin rekabetçiliğini etkileyecektir". Aynı çerçevede, rutinler-kültürel değerler arasındaki ayrım Turner ve Makhija (2006) tarafından; bilgi yaratımı bağlamında da yaratıcı rutinlerin rolü Nonaka ve Toyama (2002) tarafından dile getirilmiştir.

Bir sonraki aşamada ise bir işletme içerisinde BY uygulamalarına imkân veren altyapı (Quaddus ve Xu, 2005:108) tarafından "Bilgi Yönetim Sistemi" olarak adlandırmıştır. Buna göre bu sistemin işletmenin bilgi sermayesine dair aşağıdakileri içermesi gerekmektedir;

1-İşletmede istenen beceri ve bilgideki kişileri tespit edebilme kapasitesini yükseltebilecek çalışanlar hakkında enformasyon,

2-İşletmenin müşterileri desteklemesi ve onlara hizmet edebilmesine yardım edebilecek müşteriler hakkında enformasyon,

3-İşletmenin etkin ve verimli şekilde kaliteli ve tutarlı hizmet vermesi ile ilgili yöntem ve amaçlar ile ilgili enformasyon,

4-İşletmeyi nerede ve ne zaman olursa güncel tutacak uygulama ve gruplar ile ilgili enformasyon. Bu bağlamda BT bu sistemin tek öğesi durumundadır.

İlgili teknolojiler dikkate alındığında ise (Benbya, Passiante ve Belbaly, 2004:204)'e göre bilgi yönetim sistemleri aşağıdaki şekilde dörde ayrılmaktadır. Bunlardan ilki içerik yönetim araçlarıdır. Bu araçlar çeşitli kaynaklardan elde edilen bilgileri entegre edip, sınıflayan ve kodlayan araçlardır. İkinci grup araçlar kişiler ya da diğer aracılar arasında bilgi paylaşımını destekleyen "bilgi paylaşımı" araçlarıdır. "Bilgi araştırma ve kazanma sistemleri" ise belirli bilgi keşif yetenekleri ile donatılmış bilgiyi araştırma ve bularak alma sistemleridir. Son olarak da "genel" BY sistemleri ise şirketin BY ihtiyaçları için bütünsel bir çözüm getiren sistemlere verilen isimdir. (Alavi vd., 2005)'ya göre ise bu teknolojiler firma içerisinde bilginin yaratılması, depolanması, transferi ve paylaşılması için kullanılan bilgi depoları, veri ambarları, intranetler, arama motorları, veri filtreleri ve iş birliği araçlarıdır. Yine Alavi ve Leidner (2001)'e göre ilgili teknolojiler firma içi ve firmalar arası BY uygulamalarının sağlanması, sistematik hale getirilmesi ve hızlandırılmasını sağlamaktadır.

Yukarıdaki esaslar dikkate alındığında ise bir şirkette BY'nin başarılı olabilmesi için gereken faktörler (Sharp, 2003:33) tarafından; işletme içerisindeki iletişim, ekip çalışması ve iş birliği, üst düzey ve çalışanlar tarafından BY'ye bağlılık, inovatif şirket kültürü ve işletme teknolojisinin uygulanması olarak sıralanmıştır.

\section{Bilgi yönetimi modelleri}

Modellerin ortak özellikleri ise şöyle sayılabilir

1.Bilgi yönetimine bütünsel bir yaklaşım getirmektedirler bu anlamda kişiler, süreçler, işletme ve teknoloji boyutlarını barındırmaktadırlar.

2.BY literatüründe akademisyenler, uygulayıcılar ve araştırmacılar tarafından değiştirilmek üzere değerlendirilmekte, eleştirilmekte ve tartışılmaktadırlar

3.Uygulanan modeller sahada geçerlilik ve güvenilirlik anlamında test edilmişlerdir. Modeller incelenirken Dalkir (2005)'in sınıflandırması esas alınmıştır. 
Von Krogh and Roos'un örgütsel epistemoloji modeli (1995): Bu model normalde bireysel ve sosyal bilgiyi birbirinden ayırarak "örgütsel epistemoloji modeli" ne yönelirler. Buna göre bir işletmede bireyin ve dolayısıyla işletmenin neyi nasıl öğrendikleri, öğretinin anlamı ve karşılarına çıkan engeller sorgulanır. Von Krogh ve Roos'a göre bilgi genellikle birey düzeyindedir ve diğer kişilerle kurulan bağlantılar aracılığı ile değiştirilir (Dalkir, 2005:51). Ayrıca bu bağlamda Krogh, (1998)'e göre çalışanlara verilen önem bir şirketteki bilgi yaratımını etkilemektedir. Bu modele bilgi yönetimini işletme personeli, iletişim, örgüt yapısı, üyeler arasındaki ağlar ve insan kaynakları açısından incelemekte duruma göre BY'nin uygulamasinda potansiyel engeller olarak nitelendirmektedir (Tutorials Point, 2021).

Choo'nun anlamlandırma modeli (1998): Bu modele göre "anlamlandırma" bireylerin, mevcut olayları geçmiş olaylar ile karşılaştırarak kendi gerçeklik yorumlarını yarattığı bir sistem olarak düşünülmektedir. Örgütlerde anlamlandırma 4 asamda olmaktadır: Ekolojik değişim, icra, seçim, koruma. Ekolojik değişim işletmenin çevresindeki enformasyonu çalışanlara dağıtan değişim olarak nitelendirilirken, icra aşamasında kişiler içeriğe yönelik bileşenleri manipüle (yaratma, yıkma veya düzenleme gibi) etmektedirler. Seçim ve koruma aşamalarında ise bireyler gözlenen ve icra edilen değişimlerden seçim yaparlar. Bu modele göre kişilerin bireysel bilgileri diyalog, tartışma veya hikâye anlatma yolu ile dağıtılmaktadır.

Wiig'in bilgiyi yaratma ve kullanma modeli (1993): Buna göre bilginin kullanılabilmesi için düzenli olması gerekmektedir. Bu noktadan sonra temelde bilginin farklı perspektiflerinin ifadesinde semantik ağların yardımına başvurulmaktadır. Bu model bir noktada Nonaka ve Takeuchi modelinin "içselleştirme "aşaması üzerine bir güncelleme olarak da düşünülebilir. Modelde aynı zamanda üç farklı bilgi türü de tanımlanmaktadır. Bunlar; kamusal bilgi, paylaşılan uzmanlık ve kişisel bilgidir. Kamusal bilgi dışsal, rutin olarak paylaşılan öğretilmiş bilgi çeşidi iken paylaşılan uzmanlık ise bilgi çalışanları tarafından işleri sırasında paylaşılan veya teknolojiye gömülü bilgidir. Kişisel bilgi ise içsel ve hayatın pek çok alanında kullanılan türde bir bilgidir. Fard ve Selseleh (2010) 'a göre altı çizilmesi gereken bir diğer nokta da bu modellere göre bir organizasyonun entelektüel sermayesi örgütsel bilgi süreçlerinin sonunda gelişmesi durumudur.

Boissot'un Modeli (1998): Bu BY modelinde Boissot temel olarak enformasyonu veriden "daha önceki" bilgiye dayanarak ayırmaktadır. Modelde iki adet temel önerme bulunmaktadır, bunlardan birincisi verinin yapılandırılarak enformasyona dönüştürülmesinin onu daha yayılır kılacağı; ikincisi ise daha az yapılandırılmış verinin yayılması için paylaşılan bir ortam gerektikçe onun daha yaygın bir forma sahip olabileceğidir. Bu modele göre 3 boyut bulunmaktadır. Bunlar kodlanmış/kodlanmamış, soyut/somut ve yaygın olmayan/yaygın boyutlarıdır. Bu boyutlar bir araya gelerek "Sosyal Öğrenme Döngüsü" nün 6 aşamasını oluştururlar.

\section{Nonaka ve Takeuchi'nin modeli}

Daha önce de kısaca değinildiği gibi, BY; bilginin üretimi, saklanması, dağıtılması ve uygulanması gibi kavramları içerir. Bu kavramlardan bilgi yaratılmasının paylaşımla birlikte diğer esasların yerine getirilmesi için bir kaynak görevi gördüğü de düşünülebilir. (Nonaka ve Krogh, 2009) çalışmalarında özellikle içsel bilgi ve bilgi yaratılması arasındaki ilişkiye dikkat çekmişlerdir. Paylaşım sırasında farklı tarafların da sürece katkıda bulunabileceği varsayıldığında, alternatif yaklaşımların ve bu yaklaşımlar için kullanılması gereken verilerin de artırılması gerekliliğinin ortaya çıkması olasıdır. Aynı zamanda bilginin transferi ve yenilenmesi için gerekebilecek faaliyetler de bilgi paylaşımı sırasında ortaya çıkar. Dolayısıyla bilgi paylaşımı BY'nin temelinde bulunan kritik bir kavramdır.

\section{Genel yaklaşım ve bilgi dönüşümü}

Nonaka ve Takeuchi'ye göre bilgi kavramı kişisel inançlar ile ilgilidir ve inovasyon yaratmak için kullanılan bilginin aynı zamanda ürünlere entegre de edilmesi gerekmektedir. Buna ek olarak, özellikle insanlık, doğa ve akıl gibi olgular çerçevesinde bilginin daha kolay nakledilebileceğini belirtmişlerdir. (Dalkir, 2005). İnovasyon kavramı söz konusu olduğu için; Nonaka ve Takeuchi, dışsal bilgi haricinde içsel bilginin tecrübe ile öğrenildiği ve metafor ve analoji yoluyla aktarıldığ görülürken bu noktanın bilgi dönüşüm sürecinin temelinde olduğunun altını çizmişlerdir.

Daha önce de belirtildiği gibi bilginin yayılabilmesi için yaratılması gerekliliği göz önüne alındığında çıkış noktası bilginin birey tarafından yaratıldığı gerçeğidir. Bu noktada Nonaka ve Takeuchi'ye göre 4 boyutu bulunan ve bir sonraki kısımda bahsedilecek olan sarmal aracilığıla süregelen bilgi dönüşüm süreci Şekil 1'de verilmiştir. 


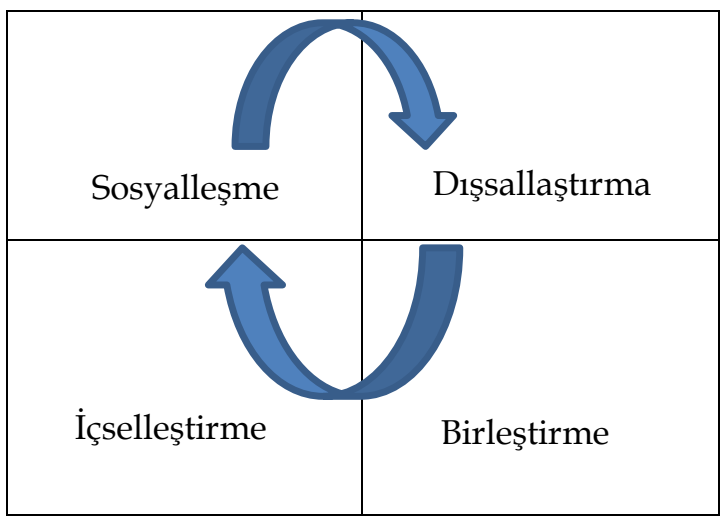

Boyut 1-İ̧sel bilgiden içsel bilgiye: sosyalleşme

Boyut 2-İçsel bilgiden dışsal bilgiye: dışsallaştırma

Boyut 3-Dışsal bilgiden dışsal bilgiye: birleştirme/bütünleştirme

Boyut 4-Dışsal bilgiden içsel bilgiye: içselleştirme

Şekil 1: Nonaka ve Takeuchi'ye göre Bilgi Dönüşüm Süreci

Kaynak: Dalkir, 2005:53

Sosyalleşme: Sosyalleşme (Nonaka, Umemoto ve Senoo, 1996:205) tarafından "tecrübeler aracılığı ile ortak örtük bilgi yaratılması süreci "olarak tanımlanmaktadır. Yüz yüze dahil olmak üzere doğal sosyal etkileşimler ile bilgi paylaşımıdır. Bu şekilde örnek olarak yeni fikirler üretmek için tecrübeler, teknik beceriler ve gözlem içeren bilgiler paylaşılabilir. Sosyalleşme en kolay bilgi değişim yollarından biridir, bulunulan yere göre değişiklik gösterebilmektedir. Bilgi değişiminin kolay olmasının yanında sosyalleşmenin en büyük dezavantajının ise genellikle bilginin kayıt altına alınamaması nedeniyle sistematikleştirilememesi ve dolayısıyla örgütsel süreçlerde kolayca kullanılamaması olduğu düşünülebilir. Ama araştırmacılara göre içsel ve dışsal bilginin çift yönlü (dışsallaştırma ve içselleştirme şeklinde) etkileşimi çok güçlü sonuçlar doğurabilmektedir.

Dışsallaştırma: İçsel bilgiye görsel bir şekil verme ve dişsal bilgiye çevirme durumudur. Nonaka ve Takeuchi (1995, akt. Dalkir, 2005:54)'a göre bu süreç “içsel bilginin dışsallaştırıldığı özet bir bilgi süreci olarak metafor, tümevarım, konsept, önsav ya da modellerin şeklini alır" olarak tanımlanmıştır. Kolay sayılamayacak bu süreçte ise bilgi konsept veya örneğin kullanma kılavuzu gibi yazılı bir şekilde kodlandığ 1 için işletme içerisinde yayılması da kolay olabilmektedir. Aslında bu boyutta bilgi bir şekilde paylaşılmaya hazır bir biçimde sunulmaktadır.

Birleştirme: Nonaka ve Takeuchi modeline göre kombinasyon durumunda açık ve işletme dişında da bulunabilecek bir bilginin birbirlerinden bağımsız parçalarını bir araya farklı bir form altında getirme veya organize etme durumudur. (Nonaka ve Konno, 1998:44)'e göre burada iletişim, yayma süreci ve bilginin sistematize edilmesi anahtar rol oynamaktadır. Bir başka deyişle kombinasyon dışsal bilginin başka bir dişsal bilgiyle kombine edilmesidir. Bunlara örnek olarak bir denetleme raporunun sentezlenmesi, kısa bir yönetici özeti veya içeriğin görüntülenip düzeltilebilmesi için bir veri tabanı olabilir (Dalkir, 2006: 55). Bu tür veri tabanları aynı zamanda örneğin; öğretilecek olan bilginin sınıflandırıldığı ve kavramların bir araya getirildiği veri tabanları olabilir. Bu bilgi aynı zamanda öğretilmek üzere farklı şekillere dönüştürülebilir.

İçselleştirme/içselleşme: Dönüşüm sürecinin son aşaması olarak dışardan alınan bilginin yayılması ve entegre (örneğin iş süreçleri ile) birleştirilmesidir. Bireyler için bir anlamda "yaparak öğrenme" de bilginin içselleştirilmesi olarak düşünülebilir. İçselleştirilen, yani az da olsa değiştirilen yeni bilgi, çalışanlar tarafından kullanılır, genişletilir ve mevcut taktiksel bilgi birikimini yeniden şekillendirmek için kullanılabilir. Aynı zamanda işletme paylaşılan bilgi dokümanları ile birlikte güçlendirilerek idrak edilir.

\section{Bilgi sarmalı ve ilgili çalışmalar}

Bilgi yaratılması çerçevesinde, bir önceki bölümde incelenen 4 adet sürecin birbirleri ile bütünleşik ve dinamik etkileşiminin olduğu düşünülmektedir. Bu bağlamda ardışık olmayan bu süreçte bilgi aynı zamanda nakledilerek paylaşılmaktadır. Bir önceki bölümde değinilen 4 boyutun kısalması olan "SECI" model olarak da bilinen "Nonaka ve Takeuchi'nin bilgi sarmalı" modelinde bir bilgi döngüsü bulunmakta ve bu sarmal içerisinde dışsal ve içsel bilgi sürekli olarak etkileşimde kalmaktadır. Bu sürecin sonunda yeni bilgi üretilmektedir. (Nonaka vd., 2000:8)'e göre bilgi üretimi SECI-dışsal ve örtük bilgi arasındaki dönüşüm, 4 farklı türü (Nonaka, Reinmoeller ve Senoo, 1998) bulunan "Ba" bilgi üretimi için paylaşılan bağlam ve bilgi üretim süreci için gereken girdi, çıktı ve moderatör rolü üstlenen bilgi aktiflerinden oluşmaktadır. Bu modelin temelinde kişilerde bulunan bilgilerin diğer bireylerle paylaşıldığı ve bu şekilde bilgi ve yeni bilginin birbirlerine bağlandığı yatmaktadır. Sarmal ne kadar çok tur yaparsa bilgi de o kadar artış gösterecektir (Knowledge Management, 2021). Bilgi sarmalı Şekil 
2'de gösterilmiştir. Bu bağlamda liderlik de önemli bir rol oynamaktadır (Nonaka Nonaka, Sasaki ve Ahmed, 2003). Özellikle bilginin çevreyle etkileşimli dinamik bir ortamda ortaya yaratılacağı göz önüne alındığında, bu yaratım sürecinin yönetimi bu etkileşimleri duruma göre sağlamayı ve yönetmeyi gerektirmektedir (Nonaka ve Toyama, 2007:377)

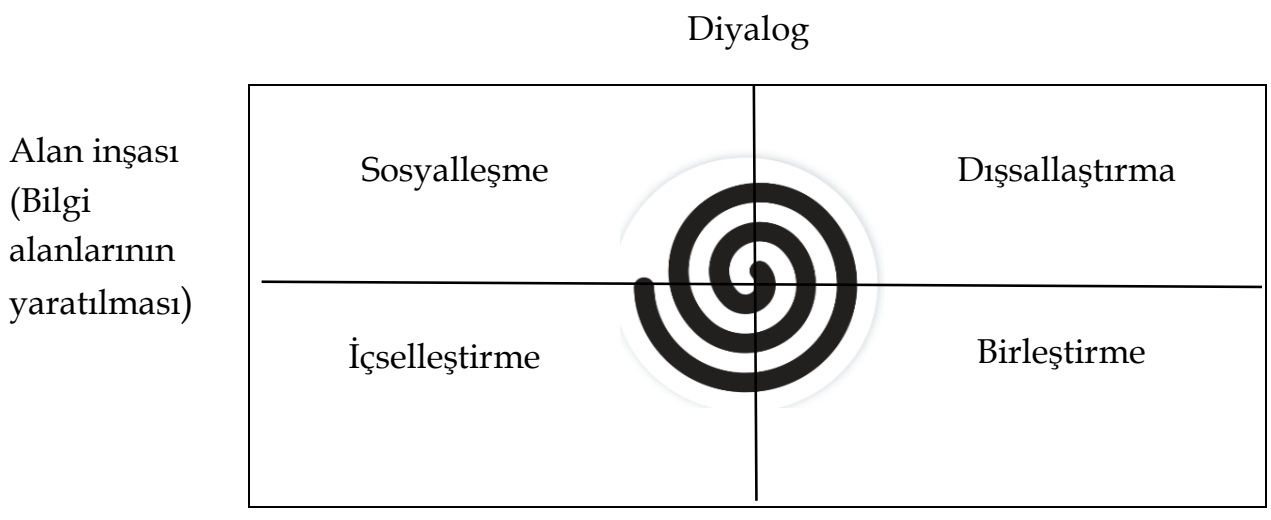

Dışsal bilgi ile bağlantı

Yaparak öğrenme

Şekil 2: Bilgi Sarmalı

Kaynak: Dalkir, 2006:57

Bu sarmal sırasında değişen dışsallaştırma içsel bilgiye göre değişirken, içselleştirme de açık bilgiyi uygulamalı bir hale dönüştürecektir. Bu iki durum çok ciddi bir kişisel bağlılık gerektirirken aynı zamanda kişilerin zihinsel model, inanç ve değerlerini işletme çapında çok iyi ifade etmelerini gerektirecektir. Buna örnek olarak bir slogan veya sembolün veya analojinin karmaşık anlamlara gelebilmesi verilebilir. Ama yaratılan zihinsel modeller ne kadar mevcut modeller ile tutarlı ve uyumlu olursa bu sarmal aracılığıyla yayılıp uygulanmaları da o kadar olacaktır (Dalkir, 2005:57).

Nonaka ve Takeuchi'nin bilgi yaratımı ve sarmalın rolü ile ilgili literatürü çeşitli gruplar altında değerlendirmek mümkündür. İlk grup çalışmalar doğrudan model ile ilgili yapılmış çalışma örneklerinden oluşmaktadır (Rose, Hawryszkiewycz ve Kang, 2014; Wu, Senoo,ve Magnier-Watanabe, 2010; Kaiser ve Fordinal, 2010; Li, Liu ve Zhou, 2018; Kang, Zhao ve Liu, 2021). İkinci grup çalışmalar ise modele doğrudan ya da dolaylı olarak atıfta bulunan çalışmalar olarak nitelendirilebilir. İlgili literatür incelendiğinde ise konu ile ilgili inovasyon ve inovasyona bağlı olgular, Merx-Chermin ve Nijhof, 2005; Amalia ve Nugroho, 2011; López-Cabarcos, Srinivasan ve Vázquez-Rodríguez, 2020), proje yönetimi (Lievre ve Tang, 2015; Serino, Papa, Campanella ve Di Giola, 2020) ve özellikle öğrenme ve eğitim ile ilgili çalışmaların (Fidalgo-Blanco Sein-Echaluce ve García-Peñalvo,2015; Tian, Nakamori ve Wierzbicki 2009; Duangchant, Kiattikomol ve Kaewkuekool, 2016; Chatterjee, Pereira ve Sarkar, 2018) daha yoğunlukta olduğu görülmektedir.

Modele atıfta bulunan bir diğer grup çalışma ise sektörel bazda yapılmış çalışmalardır. Sektörler incelendiğinde ise bankacılık (Campanella, Derhy ve Gangi, 2019), mimari (Lu ve Sexton, 2006), inşaat sektörü (Hastie, Sutrisna ve Egbu, 2017), madencilik (Mitchell ve Leach, 2017) ve turizm sektöründe (Sigala ve Chalkiti, 2014; Nezakati, Amidi, Yah Jusoh, Moghadas, Abdul Aziz ve Sohrabinezhadtalemi, 2015) modele göre bilgi yaratılması ile ilgili çalışmaların olduğu görülmektedir. Dördüncü grup çalışmalar ise işletme içi süreçlerin (yönetim ile ilgili olanlar da dahil olmak üzere) model ile ilgili bağlantılarının yine doğrudan ya da dolaylı olarak incelendiği çalışmalar olarak karşımıza çıkmaktadır. Bu süreçlere örnek olarak ekip performansı (Janhonen ve Johanson, 2010), kişisel bilgi (Cheong ve Tsui, 2010), yeni ürün geliştirme (Richtnér, Åhlström ve Goffin, 2013), bilgi sistemleri (Herschel ve Jones, 2005) veri yönetimi (Cox ve Tam, 2018) ve yazılım (Singh ve Gautam, 2016) verilebilir.

Son grup çalışmalar ise işletmeler türleri bazında yapılmış çalışmalardır. Bunlardan aile işletmeleri (Brännback, Carsrud ve Schulte 2008; Duh, 2014) ve girişimcilik (Fong ve Detwiller, 2009) ile ilgili çalışmalar gözlemlenirken (Spraggon ve Bodolica, 2008) çalışması küçük boyutta teknoloji yoğun işletmeler üzerinde yapılmış bir araştırma olarak hem araştırma alanı hem de yöntem olarak bu çalışmaya en yakın çalışma olarak düşünülebilir. 


\section{Yöntem}

Nonaka ve Takeuchi'ye göre, bir işletmede bilgi yaratılabilmesi yönünde sarmalın oluşumu için gereken şartlar 5 başlık altında sınıflandırılmaktadır (Dalkir, 2005:58). Bunlar eğilim, otonomi, dalgalanma ve yaratıcı kaos, gereğinden fazlalık (bilgi stoku anlamında) ve talep çeşitliliğidir. Bu başlıklar aşağıdaki şekilde tanımlanmıştır.

1. Eğilim: Bir işletmenin amaçlarına ulaşma isteği (bu stratejinin işletme için yaratılması)

2. Otonomi: Şirketteki bireylerin (minimum kritik özellikler-kişilerin yetenek ve donanımları ile ilgili olarak) otonom bir şekilde hareket edebilmeleri ve bu şekilde kendi kendini organize eden ekiplere katilabilmeleri

3. Dalgalanma ve yaratıcı kaos: Bir işletme ve dış çevresi arasında etkileşimi yaratan şartlar ve/veya dalgalanmaları yaratan yaratıı kaos veya stratejik belirsizlik araçları (dış çevrede bilginin belirsiz/kaotik bulunma profili nedeniyle etkileşimde meydana gelen farklılıklar)

4. Gereğinden fazlalık (bilgi birikimi anlamında): İşletme üyelerinin (çalışanların) operasyonel ihtiyaçlarının ötesine giden mevcut bilgi stoku, ayn sorunu çözmeye çalışan birden fazla ekip ve personelin stratejik rotasyonu.

5. Talep çeşitliliği: İşletme dış çevresinin karmaşık yapısına denk gelecek şekilde işletme içerisinin çeşitli olma durumu ve bu çeşitliliğin ihtiyaç duyulan bilgiye en hızlı şekilde ulaşılması için kullanılması (farklı bilgi seviyelerindeki ve konularda uzman kişiler ne kadar fazlaysa ihtiyaç duyulan bilgi talebi de o kadar çeşitlenecektir mantığı ile hareket ediliyor). Bilgi ağlarına erişim için yatay ve esnek organizasyon yapısının olup olmadığı.

İlgili literatüre göre sarmal bazlı bilgi dönüşümü araştırmalarının genellikle büyük ölçekli işletmelerde yapılmış olduğu gözlemlenmiştir (Nonaka vd., 1998, Nonaka vd., 2003, Nonaka ve Konno, 1998). Buna bağlı olarak klasik anlamda işletmelere göre daha "yeni nesil" sayılabilecek kuluçka firmaları ve buna benzer işletmeler için bilgi döngüsünün sorgulanmasının farklı sonuçlar getirebileceği düşünülebilir. Araştırma için yapıları da göz önüne alındığında özellikle bilgi yoğun ürün ve hizmetler ürettikleri savıyla kuluçka firmaları seçilmiştir. Çalışmanın da araştırma sorusu "mikro ölçekte işletmelerde sarmal bazlı bilgi dönüşümünün olabilmesi için gerekli şartların bulunmakta mıdır?" şeklinde düşünülmüştür. Bu başlıklara bağlı olarak, mikro ölçekte işletmeler dahilinde sarmal oluşumu için gerekli şartların varlığının ölçülebilmesi için bir Üniversiteye bağlı kuluçka merkezinde bulunan toplam 15 firmadan 9 tanesinin yöneticilerine derinlemesine mülakat yöntemi ile 13 adet soru yöneltilmiştir. Araştırma 2021 yılı Nisan ayı içerisinde yapılmıştır. Soru dağılımı; "eğilim" ile "dalgalanma ve yaratıcı kaos" başlıkları ile ilgili ikişer, geri kalan başlıklar için ise üçer soru şeklindedir. Bu çalışma bir üniversitenin kuluçka merkezinde yapılmıştır. Araştırma alanı olarak bir üniversitenin kuluçka merkezindeki firmaların seçilmiş olmasının bazı nedenleri bulunmaktadır. Çalışan sayısının genel anlamda 2-8 kişi arasında değiştiği mikro ölçekli bu firmalarda bilgi döngüsünün daha dinamik bir şekilde işletilebileceği beklentisi ve firmaların daha bilgi yoğun üretim yapıları araştırma alanının özellikle kuluçka merkezi olarak seçilmesine katkıda bulunmuştur. Bu bağlamda kuluçka firmalarının üretim yapıları bakıldığında robotik sistemler, optik haberleşme, süreç mühendisliği, elektronik cihaz üretimi ve kan şeker ölçümü cihazları gibi ürünler karşımıza çıkmaktadır. Buna bağlı olarak da şirketlerde bilgi sarmal oluşum şartlarının önemli olduğu düşünülebilir. Derinlemesine mülakat yapıldıktan sonra çalışmada elde edilen içerik, kodlama yöntemiyle incelenmiş ve tablolar halinde verilmiştir. Bu şekilde verilen cevaplardaki ifadelerin sıklığı anlaşılmaya çalışılmıştır.

\section{Bulgular}

Konu ile ilgili işletmelerin görüşleri bir önceki bölümde belirtilen başlıklar altında aşağıdaki şekilde verilmiştir.

Tablo 1: Eğilim Kategorisine Dair Bulgular

\begin{tabular}{|l|l|}
\hline \multicolumn{1}{|c|}{ Kodlar } & Katılımcılar (İşletme) \\
\hline TÜBïTAK projeleri ve sektör bazlı projelerde amaçlar & 6 \\
\hline Akademik işbirliği ve bağlı konuların amaçlanması & 6 \\
\hline Motivasyon & 7 \\
\hline Kendi stratejisi & 5 \\
\hline Piyasaya göre strateji/esnek strateji & 5 \\
\hline Bilgiye dayalı stratejiler & 4 \\
\hline
\end{tabular}


Eğilim: İşletmenin amaçlarına ulaşma isteği değerlendirildiğinde, işletmelerin hedeflerini belirledikten sonra amaçlarına ulaşma isteğinin genellikle yüksek olduğu görülmektedir. Özellikle işletmelerin ürettikleri ürünlerde kantitatif olarak belirlenen amaçların dışında Ar-Ge ve bilgiye dayalı (eksik kalan bilgilerin gerektiği zaman dışarıdan alınması da dahil olmak üzere) amaçlara erişim istediğinin yüksek olduğu görülmektedir. Ayrıca TÜBİTAK projeleri başta olmak üzere, farklı projelere dayalı amaçlara da ulaşma konusunda işletmelerin istekli olduğu gözlemlenmiştir. İşletmelerin çoğu tarafından da akademik iş birliğine dayalı çalışmaların da artırılması ve sektör bazlı projelere adaptasyon konusunda da belirlenen amaçların takip edilmesinin önemli olduğu vurgulanmıştır. İşletmeler tarafından dile getirilen diğer amaçlar ise şu şekilde sıralanmaktadır: doktora tezleri ile ilgili çeşitli çalışmaların yapılması, ürün geliştirme ile ilgili projeler ve sistem iyileştirmeye yönelik projeler. Genel anlamda amaçlara erişim açısından motivasyonun yüksek olduğu görülürken, bir işletme ise pandemi ortamına rağmen amaçlara ulaşma motivasyonunun düşmemiş olduğunu belirtmiştir. Aynı işletmelerin yarıya yakını da amaçları kovalama noktasında herhangi bir sınırlamasının piyasa fırsatları bağlamında olmadığını belirtmiştir.

İşletmenin amaçlarının belirli bir strateji dahilinde belirlenip belirlenmediği konusuna ise işletmelerin yaklaşımlarının bazı farklılıklar gösterdiği belirlenmiştir. Bu bağlamda, işletmelerin belli bir grubunun sadece kendi alanında teknik detaylı stratejiler belirlediği gözlenebilmektedir. Farklı stratejiler geliştirilmesi konusu işletmenin boyutu ve üretim piyasası bağlamında değerlendirildiğinde ise bazı işletmelerin piyasanın durumunun değerlendirilerek esnek bir yaklaşım içerisinde derinlemesine olmadan geliştirilebildiğini eklemiştir. Strateji belirleme noktasında bir başka yaklaşım da özellikle ürün geliştirme aşamasında bilgi havuzunun geliştirilmesi motivasyonudur. Bu yaklaşım da yine esnek bir yaklaşım olarak değerlendirilmektedir. Bunun yanında yapılan ihtiyaç analizlerine göre proje bazında derinlemesine bazı spesifik (özel) stratejilerin geliştirilmesi ve örneğin STEM eğitimi gibi eğitimlerde daha çok dar alanlarda strateji geliştirilme eğiliminin olduğu gözlemlenmiştir. Bu tür yaklaşımlar da bilgi bazlı stratejiler olarak algılanabilir.

Tablo 2: Otonomi Kategorisine Dair Bulgular

\begin{tabular}{|l|l|}
\hline Kodlar & Katılımcılar (İşletme) \\
\hline Müzakere yoluyla karar alma/ortak karar & 7 \\
\hline Gruplar arası karar transferi & 1 \\
\hline Yetkinliğe göre karar alma mekanizması & 5 \\
\hline Yöneticinin karar alması & 3 \\
\hline Ürün/proje spesifik karar & 1 \\
\hline Mevzuat bazlı & 1 \\
\hline Birimler arası ekipler bazında karar & 5 \\
\hline Bireysel karar & 1 \\
\hline
\end{tabular}

Otonomi: İşletmede çalışan personelin aldığı kararların otonom olup olmadığı değerlendirildiğinde ise farklı yaklaşımların var olduğu gözlemlenmiştir. Bu bağlamda, işletmelerin çoğunun kararları çalışanlar arasında müzakere ederek aldığı bir başka deyişle ortak karar mekanizmasının var olduğu görülürken diğer bir işletmede ürün spesifik, diğerinde ise proje bazlı bir yaklaşımın olduğu görülmektedir. Karar bazlı yaklaşımlar ele alındığında ise kritik kararların belirli kişilerce, diğerlerinin ortak, bir işletmede ise ürün/proje bazlı olarak otonominin değiştiği belirtilmiştir. Bu aşamada karar mekanizmasını şekillendiren ve karar sürecine katılan paydaşlar da işletmeler tarafından dile getirilmiştir. Bunlardan proje sırasında çalışılan danışmanlar, akademisyenler ve danışman firmalar olarak sıralanmaktadır. Son olarak bir işletme de kararların genellikle grup bazlı alındığını, iki gruptan birinin otonom aldığı kararı diğerine transfer ve otonom olmayan bu grup tarafından kararın sonlandırıldığın belirtmiştir.

Kararların tasarım sürecinin aşamalarında nasıl alındığı ile ilgili soruya ise işletmeler tarafından farklı cevaplar verilmiştir. Bu bağlamda, ilgili aşamalarda kararlar verilirken ana paketlerde daha çok yöneticilerin karar verdikleri, bunun yanında ise işlere ve gereksinimlere ve teknik şartlara göre de karar alınabildiği gözlemlenmiştir. İlgili aşamalarda sorumluluğun uzmanlıklarına ilgili kişilere verilerek denetlendiği de görülmektedir. Bunlara ek olarak, aşamaların haricinde kararlara bütünsel bir yaklaşım getirilmesi ve aşamalardan bağımsız olarak da kararların tek seferde alınması da gözlemlenen esaslar arasındadır. Ayrıca bir işletme tarafından ilgili mevzuat da süreci etkileyen bir parametre olarak belirtilmiştir. 
Kararların birimler arasındaki ekipler tarafından alınıp alınmaması ile ilgili yaklaşım ise önceki cevaplara göre daha standart bir yaklaşım sergilemektedir. İşletmelerin yarıya yakını birimler arası ekipler tarafından kararların alındığını belirtmişlerdir. Burada ekip dışında kararların alınmasını etkileyen faktörler ise işletmeler tarafından iş süreçleri ve kişilerin uzmanlık dereceleri olarak ifade edilmiştir. Örnek vermek gerekirse, birimlerin uzmanlık düzeylerine göre ağırlıklı olarak süreçlerin gerekliklerine göre belirli kişiler de tek başlarına karar alabilmektedirler. Burada süreç gerekliliklerinden kasıt ise daha çok teknik yoğunluk ya da liderlik ve donanım ve yazılım altyapısı gibi proje yönetimi ile ilgili konular olmaktadır.

Tablo 3: Dalgalanma ve Yaratıcı Kaos Kategorisine Dair Bulgular

\begin{tabular}{|l|l|}
\hline Kodlar & Katılımcılar (İşletme) \\
\hline Akademik teşvik mekanizması & 2 \\
\hline Girişimcilik/rekabet & 2 \\
\hline Bilgi (ölçme-değerlendirme) bilgi araştırması & 2 \\
\hline Ar-Ge-Bağlı diğer konular & 3 \\
\hline Müşteri ilişkileri & 1 \\
\hline Proje yönetimi & 3 \\
\hline Çalışanların yaratıcılığı & 1 \\
\hline Yenilikçilik/inovasyon/patent & 4 \\
\hline
\end{tabular}

Dalgalanma ve Yaratıcı Kaos: İşletmedeki ortam ve dış çevre arasındaki süreç ile ilgili soruya ise çok farklı cevaplar verildiği görülmektedir. İşletmelerde genel anlamda etkileşimin yüksek olduğu görülmekle birlikte etkileşim ve dış çevre bağlamında alanların da oldukça farklı olduğu gözlemlenmiştir. Bu aşamada, örneğin çalışanların yüksek lisans eğitimlerini teşvik mekanizması ile ilgili etkileşim, Ar-Ge ve girişimcilik ile ilgili konular, araştırma kaynaklarına erişim ve etkileşim sonunda elde edilen bilgilerin içselleştirilmesi ve etkileşim sonucunda elde edilen bilgilerle tasarlanan süreçlerin ölçme ve değerlendirilmesi, yeni bilgilerin araştırılması ve rekabet gibi konular işletmeler tarafından etkileşim alanları olarak belirtilmiştir.

Bir önceki soruya benzer olarak, "Yaratıı kaos" ile ilgili yaklaşımlar da işletme-çevre bağlamında farklılıklar göstermektedir. Yine genel anlamda "yaratıcı kaos" işletme ortamı tarafından desteklenmekte fakat desteklendiği konular işletmeler bazında farklılıklar göstermektedir. Örneğin, müşteri ilişkileri yaratıcı kaosun desteklendiği bir alan olarak ortaya çıkmaktadır. İşletmeler tarafından diğer konular ise, inovasyon, patent, sistem performansının artırılması gibi konular şeklinde görülmektedir. İşletmelerden üç tanesi ise yaratıcı kaos kavramını proje yönetimi içerisinde ele almışlardır. Buna göre, yaratıcı kaos yaklaşımı proje süreçlerindeki engellerin aşılması ve finansman sağlanması gibi mali konular ile bağdaştırılırken, bir işletme ise yaratıcı kaos yaklaşımını projenin ürüne dönüşmeden önceki son aşamada benimsediğini belirtmiştir. Bir işletme ise bu yaklaşım için daha çok insanların da yaratıcılığının etkili olduğunu ve özellikle bu yaklaşım için çalışanların hayal güçleri başta olmak üzere çalışanların yaratıcı ve yenilikçiliğinin artırılması için gerekli destek ekipmanları ve bilgi kaynaklarını onlara sağladıklarını belirtmişlerdir. Fakat genel anlamda firmaların yarıya yakını yenilikçiliği daha inovatif ve fikri mülkiyet hakları bağlamında algılamaktadırlar.

Tablo 4: Gereğinden Fazlalık Kategorisine Dair Bulgular

\begin{tabular}{|l|l|}
\hline Kodlar & Katılımcılar (İşletme) \\
\hline Bilgi miktarı fazlalığı & 4 \\
\hline Duruma göre değişken araştırma bazlı bilgi miktarı/deneme yanılma- & 4 \\
\hline Ekosistem & 1 \\
\hline Derinlemesine bilgi depolama & 2 \\
\hline Birden farklı işte yetkinleşme & 7 \\
\hline Rotasyon/benzer işler & 5 \\
\hline Rotasyon/diğer/ă̆ yapı & 4 \\
\hline
\end{tabular}


Gereğinden Fazlalık: Genel anlamda fazla bulunmakla birlikte, bilgi stokunun çalışanlar için miktarı ile ilgili soruya da farklı yaklaşımlar getirilmiştir. Alınan cevaplara göre bu yaklaşımlar sadece bilgi miktarı ile ilgili olmanın yanında bir işletme tarafından da içinde bulunulan ekosistem ve araştırmanın amacıyla bağlı olarak bilgi türü bağlamında da yorumlanmıştır. Bunlara örnek olarak çekirdek bilgi, alan bilgisi ve müşteri ile ilgili bilgiler verilmiştir. İki işletme bilgi stokunun oluşturulması noktasında bilginin mümkün olduğu kadar derinlemesine depolanmasının altını çizerken diğer bir grup işletmeye göre bilginin depolanması deneme-yanılma yöntemi ile de yapılabilmektedir. Araştırmaya dayalı bilginin önemine de dikkat çekilmiş, bu tür bilgilerin de duruma göre değişen yoğunlukta değerlendirilmesi gerekliliği belirtilmiştir. Ayrıca belli durumlarda bütçe ve personel durumu bilgi stokunu da etkileyebilmekte ve yine bu bağlamda gerekli görülmeyen veya ihtiyaç duyulmayan bilgiye erişim tercih de edilmeyebilmektedir.

Ekiplere birden fazla işte yetkinleşme fırsatlara verilen cevaplar işletmeler arasında genellikle paralellik göstermektedir. Bunun temel nedeni olarak da işletmedeki çalışanların yeteneklerinin çoklu göreve müsait olması ve değişen piyasa şartları olduğu söylenebilir. Bu bağlamda bu yetkinleşme bazı firmalara göre mecburi şekilde de yapılabilmektedir. Burada çalışanların birbirlerinin görevlerini spesifik konular dışında hâkim olabilmeleri için bir sonraki soruda bahsedilen rotasyon veya farklı planlama şekilleri ile diğerinin işinde de yetkinleşme fırsatları sağlanmaktadır. Ayrıca, bir işletme da yine görev bazında tam olarak olmasa da kısmen yetkinleşme fırsatı verdiğini belirtmiştir.

Şirket stratejisinin rotasyonu destekleme bağlamında ise verilen cevaplar genellikle bir önceki başlı̆̆a bağlı olarak şirketlerin genel anlamda rotasyonu destekledikleri şeklindedir. Burada farklılıklar ise genellikle işletmenin rotasyonu destekledikleri yönler ya da noktalar arasında görülmektedir. Örneğin bir grup işletme benzer işler arasında rotasyonu desteklerken, diğer bir grup dış paydaşların ilgili birimleri ile rotasyonu tercih etmektedir. Bu bağlamda dışarıdaki başka bir işletmenin elektroniktasarım altyapısının kullanılması da bir rotasyon türü olarak düşünülebilmektedir. Bir işletme ise özellikle yazılım türleri arasında rotasyon imkânları sağladığını belirtmiştir. Diğer bir işletme temel stratejilerinin kişinin bir işte yetkinleşmesi olduğunu amaçlamakla birlikte ise rotasyon imkânlarının desteklenmesi için özellikle çalışanlarına sağladığı eğitim içeriklerine dikkat çekmiştir. Bu bağlamda eğitim içeriklerini ise çevrimiçi ve video şeklinde sıralamıştır. Ayrıca işletmelerin ağ yapı içerisinde bulunmaları da rotasyonu kolaylaştıran bir faktör olarak karşımıza çıkmaktadır.

Tablo 5: Talep Çeşitliliği Kategorisine Dair Bulgular

\begin{tabular}{|l|l|}
\hline Kodlar & Katılımcılar (İşletme) \\
\hline İçsel-dışsal taleplerin karşılanması & 5 \\
\hline Farklı uzmanlık türleri & 3 \\
\hline Bilgi için ekip kurulumu & 2 \\
\hline Bilgiye yeterli erişim/motivasyon & 8 \\
\hline Ar-ge-diğer araştırma konuları & 5 \\
\hline Süreç bazında spesifik bilgi & 1 \\
\hline Kazanç/inovasyon & 1 \\
\hline Yeni projeler & 5 \\
\hline Teknokent bağlantılı erişim & 6 \\
\hline
\end{tabular}

Talep çeşitliliği: Dış çevreden gelecek taleplerin personel bazında karşılanması bağlamında tüm işletmeler farklı altyapıda personellerinin bulunduğunu belirtmişlerdir. Bir işletme haricinde bu aşamada, gelen taleplerin nasıl karşılandığına dair farklı yaklaşımlar bulunmaktadır. Farklı bilgi türlerinde (içsel-dışsal) gelen taleplerin karşılanması, farklı taleplerin karşılanması için uzmanlık alanına göre alım yapılması, gerekirse dış kaynak kullanımı buradan elde edilen hizmetlerin geliştirilmesi ve planlama gibi konular işletmeler tarafından belirtilen ilgili alanlara işaret etmektedir. Bunun dışında bazı şirketler taleplerin karşılanması için ekipler de kurduklarını belirtmişlerdir. Bütçe ve süreç gereksinimleri ise ilgili taleplerin karşılanması bağlamında ortaya çıkan kısıtları oluşturmaktadır.

Çalışanların bilgiye erişimi noktasında ise işletmelerin genel yaklaşımları çalışanların bilgiye erişimleri olduğunu ve çeşitli şekillerde bu erişimin desteklendiği ve bu yönde motivasyonun yüksek olduğu şeklindedir. Pazar araştırması, satış-tanıtım, Ar-ge ve araştırma konuları ve diğer bilimsel konular genellikle erişimi istenen bilgi başlıklarını oluşturmaktadır. Ayrıca süreç bazında spesifik bilgiler de 
erişimi amaçlanan bilgi başlıkları olarak belirtilmiştir. Özellikle yönetim desteği konusunda bir işletme bu bilgilere erişim konusunda önayak oldukların belirtirken gerekirse bunun için ayrı bir ekip de kurduklarının altını çizmiştir. Bütçe kısıtları kaynaklı çeşitli erişim sorunları da bazı işletmeler tarafından sinırlılıklar olarak dile getirilmiştir.

İşletme yapılarının bilgi ağlarına erişimi noktasında ise farklı yaklaşımların hâkim olduğu görülmektedir. Bunun temel sebebi olarak da bilgi ağlarından elde edilecek getirideki farklı algılar olduğu düşünülebilir. Bu getirilere örnek olarak kazanç, inovasyon kapasitesinin artırılması (bir işletme), yeni teknolojiler, sinerji kazanımı, yeni proje başvuruları ve diğer şirketler ile iş birliklerinin geliştirilmesi, Teknokentler dahilinde yarışmalara katılım ve mentörlere erişim sayılmaktadır.

\section{Tartışma}

İşletmelerin genel anlamda konuya yaklaşımları özetlendiğinde bilgiye erişim, rotasyonun desteklenmesi, ekip çalışması ve amaçlara ulaşma isteği genellikle tüm işletmelerde yüksek bir seyir izlerken diğer başlıklarda farklı yaklaşımlar gözlemlenmektedir. Alternatif bir yaklaşımla ise sarmal şartlarını sağlamak açısından kısmen de olsa "talep çeşitliliğii", "gereğinden fazlalık" ve "eğilim" ve başlıklarında ortak paydaya erişilebildiği gözlemlenmektedir.

Diğer taraftan şartlar tek tek incelendiğinde ise işletmeler bazında bilgi sarmalını oluşturabilecek şartların daha çok "eğilim" ve "gereğinden fazlalık" başlıkları üzerine oturduğu düşünülebilir. Burada altı çizilmesi gereken nokta aslında genel anlamda diğer başlıklar üzerinde de dinamik yaklaşımların bulunduğu ama yaklaşım türlerinde farklılıklar gözlemlenebildiğidir. Bu açıdan da sürecin dinamik bir şekilde işlemesi Alavi ve Leidner (2001:131)'nin BY'nin işletme içerisinde süreklilik ve dinamizm arz ettiğine işaret eden bulguları ile tutarlılık göstermektedir. İşletmeler arası farklıkların temel nedenleri arasında değişen piyasa şartları, bütçe kısıtları, süreç farklıkları ve dolaylı olarak müşteri talepleri sayılabilir. Özetle bakıldığında cevaplar sonunda bilgi yönetiminin değişkenlik gösterdiği bir profil ortaya çıkmaktadır. Bu olgu, bilgi sarmalı bazında düşünüldüğünde daha önce belirtilmiş olan 4 aşamanın da bu dinamizmden etkilenebileceği öngörülebilir. Bu durumda Becerra-Fernandez ve Sabherwal (2001) tarafından da önerildiği gibi iş bazında bilgi süreçlerinden tatmin olunması noktasında değişkenlik durumunun önemi ortaya çıkmaktadır. Ayrıca, piyasa entegrasyonunun özellikle işletmelerce vurgulanmış olması BY uygulamalarının Bhunia (2004:25)'nın çalışmasında da belirttiği gibi sağladığı rekabet avantajının artırılması konusunu bir kez daha gündeme getirmiştir. Çalışmada elde edilen sonuçlara göre işletmelerin çoğunun "ağ yapı" nın öneminin altını çizmesi de bu tür entegrasyon bazlı avantajlara işletmelerin eğiliminin altını çizmektedir.

Gereğinden fazlalık noktasında elde edilip depolanan bilginin işletme içi süreçlere daha iyi entegre edilebilmesi için Benbya vd., (2004)'nin önerdiği şekilde bilgi altyapı araçları bir kolaylaştırıcı olarak da düşünülebilir, bu şekilde işletmedeki entelektüel sermayenin de daha optimal kullanılması söz konusu olabilir. Zaten işletmenin bilgi yaratan bir şirket olabilmesi için de Nonaka vd., (1996:217)' da belirtildiği gibi daha önce bahsedilmiş olan BT araçlarını şirket çalışanları ile sinerjisinin sağlanması gerekliliği de burada dolaylı olarak ortaya çıkmaktadır. Yalnız bu noktada bir önceki paragrafta değinilen bütçe kısıtlarının işletmeler bazında potansiyel bir engel teşkil ettiği düşünülebilir.

Bu bağlamda altı çizilmesi gereken bir başka nokta ise Nonaka ve Konno, (1998:684)'de belirttiği gibi kişi tecrübelerinin ve içsel bilginin de Nonaka vd., (2003) BT uygulamalarını destekleyici şekilde olması gerekliliğidir. Çalışma sonuçlarına göre de işletmelerin özellikle nispeten az olan "derinlemesine bilgi depolama" mekanizmalarını bu yönde geliştirmeleri bir öneri olarak sunulmaktadır.

"Otonomi" başlığı altında göze çarpan en önemli noktalardan birinin ise karar alma mekanizmalarındaki benzerlik olduğu düşünülebilir. Bulgulara bağlı olarak işletmelerde gözlemlenen karar mekanizmalarının farklılaşması durumu Plessis (2005)'in de altını çizdiği gibi şirketlerdeki bilgi yönlendiricilerinden olan etkin karar verme olgusunun ele alınan işletmelerdeki süreçler ile taşıdığı benzerliktir. Özellikle bilgi paylaşım odaklı karar süreçlerinde çalışmada ele alınan işletmelerin bu yolu izlemeleri Fard ve Selseleh (2010:308)'ın da belirtiği gibi bilginin uygulanmasının tamamen paylaşımına bağlı olduğu gerçeğini dolaylı olsa da yansıtmaktadır.

Bunların dışında işletmelerin diğer başlıklar altındaki şartları sağlamaları, bilgi sarmalını oluşturabilmeleri ve bu yaklaşımı örgüt kültürlerinin bir parçası haline getirebilmeleri için motivasyonlarının yüksek olduğu gözlemlenmiştir. Bu yaklaşım Alavi, Kayworth ve Leidner (2005) ve özellikle bilgi süreçlerinin yönetsel süreçlere etkisi noktasında Intezari vd. (2017)'ın bulguları ile yakınsamaktadır. Bu motivasyon diğer başlıklara göre özellikle "eğilim" ile "talep çeşitliliği" başlıkları altında ortaya çıkmaktadır. Son olarak da işletmeler arasındaki en büyük farklılığın "dalgalanma ve yaratıcı kaos" başlığı altında ortaya çıktı̆̆ı görülmektedir. Buna karşın ele alınan işletmeler bazında 
yenilikçilik-inovasyon- patent üçlüsünde kategorinin en fazla ortaklı̆̆ının bulunması ise BY süreçlerinin farklı boyutlarda inovasyon yönetimine entegrasyonu noktasında daha önce bahsedilen Johanessen' (2008) ve Vaccaro, Parente ve Veloso, (2010)'ın bulgularına yaklaştığı düşünülebilir. İlk çalışmaya göre, şirketlerin bilgisel gelişimi inovasyon stratejilerini ve ikinci çalışmaya göre ise de BY araçları şirketlerin inovasyon ve finansal performansını etkilemektedir.

\section{Sonuç}

Bu çalışmada öncelikli olarak BY kavramının işletmelerdeki yapısal boyutu ve daha sonra yayılım ve dönüşüm etkileri altında bilginin yaratılması ele alınmıştır. Özellikle BY'nin yayılım etkisi göz önüne alındığında entelektüel sermaye ve bilgi sermayesinin rolünün de dikkate alarak, işletmelerin bilgi yaratılmasına uygunluğunun ölçülmesi amacıyla kuluçka firmaları ile mülakat yöntemi ile bir çalışma yapılmıştır. Bu çalışma ile de bilgi sarmalının oluşması için mikro düzeyde işletmelerin ne ölçüde hazır olduklarının belirlenmesi hedeflenmiştir.

Giriş bölümünde altı çizildiği gibi günümüzün piyasa koşullarında bilginin öneminin özellikle rekabet ve inovasyon bazlı stratejilerin tasarımında çok önemli bir rolü olduğu görülmektedir. Buna bağlı olarak da doğru ve çeşitli bilgiye düşük maliyetli şekilde ulaşılması önem kazanmaktadır. Bilginin firma içerisine çekilmesini takiben o bilginin nasıl kullanılacağı, iş süreçlerine ve strateji tasarımlarına ve Sabri (2005)'in de altını çizdiği gibi şirket kültürlerine ve kültürel temellere nasıl entegre edilmesi gerektiği ise firmanın doğru ve istenilen bilgiye uygun BY ortamı sağlaması ve uygun altyapı sistemleri ile şekillenmektedir. Bu durum, Krogh, Nonaka ve Aben (2001)'in çalışmasında belirttiği gibi bilgi bazlı strateji formülasyonunun ve seçimlerinin diğer işletme bazlı stratejiler ile eşleştirilmesinin önemini arz etmektedir. Bu şekilde firmalar, bilgiden mümkün olduğu kadar etkin bir şekilde faydalanmayı hedeflemektedirler. Bilgi yönetiminden elde edilen getirilere bakıldığında sadece araştırmada ele alınan sektörün yanında BY'nin günümüzde farklı sektörlerdeki farklı uygulama örneklerine ve önemine de Gunesekaran ve Ngai (2007)'ın çalışmasında rastlanmaktadır. Daha önce de belirtildiği gibi sadece bilginin çalışanlar nezdinde nasıl saklandığı, kullanıldığı, yayıldığı ve büyütülerek, çeşitlendirilerek artırıldığı de BY'de önemli bir konudur. Bu konuya getirilen belirli teorik yaklaşımlara da çalışmada değinilmiştir.

Bu yaklaşımlardan içsel ve dışsal bilginin etkileşimi sonucunda yeni bilgi üretimi ile ilgili sarmal yaklaşımının özellikle dinamik ve organik yapıya sahip mikro ölçekli işletmelerde ne boyutta algıladığı ile ilgili bir araştırma yapılması hedeflenmiştir. Bu işletmelerin seçilmiş olmasının nedeni hem bilgi yoğun hem de esnek yaklaşımlara daha açık olabilecekleri öngörüsü olarak düşünülebilir. İşletmelerin hem içerisinde bulunduğu alandaki bilgi etkileşimi (üniversite-sanayi iş birliği ortamı gibi) hem de benzer türde işletmelerin birbirleri ve piyasadaki diğer paydaşlar ile etkileşiminin genellikle içsel veya dışsal bağlamda bilgi yoğun olduğu düşüncesidir. Buna ek olarak işletme yönetici ve çalışanların yine bilişsel altyapıları da göz önüne alındığında BY çerçevesinde bilginin büyümesi eğilimine sıcak baktıkları da düşünülebilir. Sonuç olarak hem bulunulan çevre, üretilen ürünler hem de boyut açısından bu işletmelerin araştırma için uygun oldukları sonucuna varılmıştır.

Kısaca sonuçlarda en ön plana çıkan noktalar şu şekilde sıralanabilir; eğilim kategorisinde ekip çalışması, otonomi kategorisinde ortak karar mekanizması, gereğinden fazlalık kategorisinde birden fazla işte yetkinleşme ve talep çeşitliliğinde bilgiye yeterince erişim ve erişim imkânı sağlanması. Araştırma sonuçlarına göre işletmelerde ilk göze çarpan nokta, ölçek gözetilmeksizin genel anlamda mikro işletmelerde de bilgi yönetimi farkındalığının olduğu olgusudur. Bu anlamda işletmelerin nispeten bilgi yoğun işletmeler oldukları için ilgili bilince sahip oldukları diğer bir araştırma konusu olabilir. Sonuçlarda ön plana çıkan ilk nokta işletmelerin amaçlarına ulaşma konusunda istekli olduğu ve özellikle bu bağlamda piyasa etkileşimini ön planda tutmalarıdır. Bilgi bazında dış çevreyle etkileşiminin müşteri ilişkileri, inovasyon, patent gibi konularda ve projeler çerçevesinde işletmeler tarafından ele alınan konulardır. Yine genel anlamda tüm işletmelere bakıldığında işletmelerin bilgiyi, özellikle üretim alanında, hedefe ulaşma eğilimi yüksek bir şekilde yine bilgi yoğun stratejiler, piyasa ile etkileşim ve ortak karar verme, uzmanlaşma ve ekip mekanizması aracılığı ile kullandıkları görülmektedir. Özellikle işletmelerin piyasa ile bilgi yoğun şekilde etkileşim istekleri araştırma sorusu ile doğrudan ilişkilendirilecek bir olguya işaret etmektedir. Bu durumda araştırma boyutlarının ilk iki boyutunun işletmeler tarafından hem büyük ölçüde hem de değişik şekillerde özümsendiği gözlemlenmiştir.

Buna ek olarak, farklı türde bilginin stoklanması, rotasyon da dahil olmak üzere çalışanların birden fazla konuda yetkinleşmelerinin teşvik edilmesi gibi sarmalı oluşturan diğer faktörlerin de önemli ölçüde işletmeler bünyesinde var olduğu sonucuna ulaşılmıştır. Burada altı çizilmesi gereken noktalar özellikle depolanmak istenen bilginin ekosistemden geliyor olması ve ekosistemde mevcut bulunan 
bilgi ağlarına işletmelerin olan ilgisidir. Dolaysıyla ihtiyaç duyulan bilgiye ve buna ek olarak bilgi ağlarına erişimin yine yönetimler tarafından desteklenmesi de yine sarmalın çalışabilmesi için beklenen son boyutu da tamamlamıştır. Burada ortaya çıkan bir diğer nokta ise gelen bilgilerin değerlendirilmesi ve buna bağlı olarak taleplerin karşılanması noktasında farklı türde yetkinleşmenin bir kez daha ön plana çıkmasıdır ki bu durum göz önüne alındığında birden fazla işte yetkinleşmenin kişilerin içsel bilgi ve tecrübe dağarcığına dolaylı yönden katkı sağlaması beklenebilir. Bu durum tartışma kısmında da belirtildiği gibi yine işletmeler bazında içsel bilginin artırılması konusuna destekleyici bir olgu olarak karşımıza çıkmaktadır. Bunun nedeni ise daha önce de belirtildiği üzere içsel bilgi ve BT etkileşiminin BY uygulamalarının özümsenmesi noktasındaki olumlu katkısıdır. Yine, içsel bilgi-inovasyon bağlantısı (Seidler-de Alwis ve Hartmann, 2008) ve işletmelerin inovasyon-BY eksenindeki farkındalıkları da BY uygulamalarının rekabet avantajı sağlama noktasında olumlu bir şekilde karşımıza çıkmaktadır. Daha önce değinilen bilgi ağlarının; sadece iş ortaklıkları boyutu ile değil aynı zamanda bilgi paylaşımı sağlayacak topluluklar şeklinde düşünüldüğünde ortamın yine işletmelere inovasyon anlamında katkıda bulunma potansiyelinden bahsedilebilir. Bilgi topluluklarının rolü (Shuhuai, Xingjun, Haiqing, ve Jialin, 2009)'nin çalışmasında ortaya konmuştur.

Özet olarak ele alınan işletmelerde bilgi yaratılması için gerekli olan şartların büyük ölçüde oluşmuş olduğu söylenebilir. Bu durum, zaten BY'nin getirilerinin yararını anlamış olan işletmelerin başarılı BY uygulamaları için gerekli olan bir imkâna sahip olduğuna da işaret etmektedir.

Çalışmanın kısıtları ise ele alınan işletmelerin bazılarının çok küçük boyutta olması veya aynı zamanda işletmeler tarafından da dile getirilen kısıtlar nedeniyle bilgiye erişim ve ilgili altyapıların kurulmasında çıkabilecek çeşitli zorluklar olarak sayılabilir. Buna ek olarak daha fazla sayıda işletme üzerinde bu araştırmanın yapılması da farklı sonuçlar verebilir. Son olarak, çalışmanın daha büyük ölçekli işletmelere de uygulanması çıkabilecek farklı sonuçların karşılaştııılmasına da olanak sağlayacaktır.

\section{Hakem Değerlendirmesi / Peer-review:}

Dış bağımsız

\section{Externally peer-reviewed}

\section{Çıkar Çatışması / Conflict of interests:}

Yazar(lar) çıkar çatışması bildirmemiştir.

The author(s) has (have) no conflict of interest to declare.

\section{Finansal Destek / Grant Support:}

Yazar(lar) bu çalışma için finansal destek almadığını beyan etmiştir.

The author(s) declared that this study has received no financial support.

\section{Etik Kurul Onay1 / Ethics Committee Approval}

Bu çalışma için etik kurul onayı, Çankaya Üniversitesi, Sosyal ve Beşerî Bilimler Bilimsel Araştırma ve Yayın Etiği Kurulunun 18/03/2021 tarihli 77342 sayılı karar ile alınmıştır.

Ethics committee approval was received for this study from Çankaya University, Social Sciences and Humanities Research and Publications Committee on 03/18/2021 and 77342 document number.

\section{Kaynakça / References}

Aiai (2021, Haz.17) Artificial Intelligence Applications Institute http://www.aiai.ed.ac.uk/ alm/kam.html

Alavi, M., Kayworth, T.R \& Leidner, D.E. (2005). An empirical examination of the influence of organizational culture on knowledge management practices. Journal of Management Information Systems. 22(3): 191-224. 
Alavi, M., Leidner, D.E. (2001). Review: Knowledge management and knowledge management systems: conceptual foundations and research issues. MIS Quarterly. 25(1): 107-136.

Amalia, M., Nugroho, Y. (2011). An innovation perspective of knowledge management in a multinational subsidiary. Journal of Knowledge Management. 15(1): 71-87.

Baskerville, R., Dulipovivi A. (2006). The theoretical foundations of knowledge management. Knowledge Management Research \& Practice. 4: 83-105.

Becerra-Fernandez.I., Sabherwal R. (2001). Organizational knowledge management: a contingency Perspective. Joumal of Management Information Systems. 18(1):23-55.

Benbya, H., Passiante, G. \& Belbaly N.A. (2004). Corporate portal: a tool for knowledge management synchronization. International Journal of Information Management. 24:201-220.

Bhunia, C.T. (2004). Knowledge management: why and how. JETE Technical Review. 21(1):25-37.

Brännback, M., Carsrud, A. \& Schulte, W.D. (2008). Exploring the role of Ba in family business context. VINE: The Journal of Information and Knowledge Management Systems. 38(1):104-117.

Campanella, F., Derhy, A.\& Gangi, F. (2019). Knowledge management and value creation in the postcrisis banking system. Journal of Knowledge Management. 23(2): 263-278.

Chatterjee, A., Pereira, A. \& Sarkar, B. (2018). Learning transfer system inventory (LTSI) and knowledge creation in organizations. The Learning Organization. 25(5):305-319.

Cheong, R.K.F., Tsui, E. (2010). The roles and values of personal knowledge management: an exploratory study. VINE: The Journal of Information and Knowledge Management Systems. 40(2): 204-227.

Cox, M., Tam, W.W.T.T (2018). A critical analysis of lifecycle models of the research process and research data management. Aslib Journal of Information Management. 70(2):142-157.

Dalkir, K., (2005). Knowledge management in theory and practice. Elsevier.

Duangchant, S., Kiattikomol, P. \& Kaewkuekool, S. (2016). Knowledge transfer in B-O-R-N Model to enhance computer learners' learning outcomes in knowledge and cognitive skills. The Learning Organization. 23(2/3):170-183.

Duh, M. (2014). Family business succession as knowledge creation process. Kybernetes. 43(5): 699-714.

Fard, H.D., Selseleh M. (2010). Measuring knowledge management cycle: evidence from Iran. European Journal of Scientific Research. 41(2): 297-309.

Fidalgo-Blanco À, Sein-Echaluce, M.L \& García-Peñalvo, F. (2015). Epistemological and ontological spirals: From individual experience in educational innovation to the organisational knowledge in the university sector. Program: electronic library and information systems. 49(3): 266-288.

Fong, P.S.W., Dettwiler, P. (2009). Entrepreneurial firms and their knowledge creation: a study of real estate management. Facilities. 27(7/8): 267-276.

Gartner (2021, Tem.4) gartner.com/en/information-technology/glossary/knowledge-capital

Grover, V., Davenport, T. (2001). General perspectives on knowledge management: fostering a research agenda. Journal of Management Information Systems. 18(1): 5-21.

Gunasekaran, A., Ngai, E.W.T. (2007). Knowledge management in 21st century manufacturing. International Journal of Production Research. 45 (11): 2391 - 2418.

Hastie, J., Sutrisna, M., \& Egbu, C. (2017). Modelling knowledge integration process in early contractor involvement procurement at tender stage - a Western Australian case study. Construction Innovation. 17(4): 429-456.

Herschel, R.T., Jones, N.E. (2005). Knowledge management and business intelligence: the importance of integration. Journal of Knowledge Management. 9(4): 45-55.

Intezari, A., Taskin, N \& Pauleen D.J. (2017). Looking beyond knowledge sharing: an integrative approach to knowledge management culture. Journal of Knowledge Management. 21(2):492-515.

Janhonen, M., Johanson, J.E. (2011). Role of knowledge conversion and social networks in team performance. International Journal of Information Management. 31:217-225. 
Johannessen, J.A. (2008). Organisational innovation as part of knowledge management. International Journal of Information Management. 28: 403- 412.

Kaiser, A., Fordinal. B. (2010). Creating a ba for generating self-transcending knowledge. Journal of Knowledge Management. 14(6):928-942.

Kang, X., Zhao, D., Liu, Q. (2021). Transmission mechanism of simmelian ties on the knowledge spiral - the conducive combination of a high-performance work practice and knowledge fermentation. Journal of Organizational Change Management. 34(5):1003-1017.

Knowledge Management (2021, Haz. 21) https://knowledgeandmanagement.wordpress.com/secimodel-nonaka-takeuchi/

Krogh, G.V., Nonaka, I.\& Aben, M. (2001). Making the most of your company's knowledge: a strategic framework. Long Range Planning. 34:421-439.

Krogh, G.V. (1998). Care in knowledge creation. California Management Review. 40(3):133-153.

Li, M., Liu, H. \& Zhou, J. (2018). G-SECI model-based knowledge creation for CoPS innovation: the role of grey knowledge. Journal of Knowledge Management. 22(4): 887-911.

Lievre, P. Tang, J. (2015). SECI and inter-organizational and intercultural knowledge transfer: a casestudy of controversies around a project of co-operation between France and China in the health sector. Journal of Knowledge Management. 19(5):1069-1086.

López-Cabarcos, M.A., Srinivasan, S. \& Vázquez-Rodríguez, P. (2020). The role of product innovation and customer centricity in transforming tacit and explicit knowledge into profitability. Journal of Knowledge Management. 24(5): 1037-1057.

Lu, S.L., Sexton, M. (2006). Innovation in small construction knowledge-intensive professional service firms: a case study of an architectural practice. Construction Management and Economics. 24:12691282.

Merx-Chermin, M., Wijhof, W.J. (2005). Factors influencing knowledge creation and innovation in an organisation. Journal of European Industrial Training. 29(2):135-147.

Mitchell, R.E., Leach, B. (2019). Knowledge coproduction in environmental impact assessment: Lessons from the mining industry in Panama. Environmental Policy and Governance. 29:87-96.

Nezakati, H., Amidi, A., Yah Jusoh, Y., Moghadas, S., Abdul Aziz, Y. \& Sohrabinezhadtalemi, R. (2015). Review of social media potential on knowledge sharing and collaboration in tourism industry. Procedia - Social and Behavioral Sciences. 172:120-125.

Nonaka, I., Umemoto, K. \& Senoo, D. (1996). From information processing to knowledge creation: a paradigm shift in business management. Technology in Society. 18(2):203-218.

Nonaka, I., Reinmoeller, P.\& Senoo, D. (1998). The 'art' of knowledge: systems to capitalize on market knowledge. European Management Journal. 16(6):673-684.

Nonaka, I., Konno, N. (1998). The concept of Ba. Building a foundation for knowledge creation. California Management Review. 40(3):40-54.

Nonaka, I., Toyama, R.\& Konno, N. (2000). SECI, Ba and leadership: A united model of dynamic knowledge creation. Long Range Planning. 33:5-34.

Nonaka, I, Toyama, R. (2002). A firm as a dialectical being: Towards a dynamic theory of a firm. Industrial and Corporate Change. 11(5): 995-1009.

Nonaka, I., Sasaki, K.\& Ahmed, M. (2003). Continuous innovation in Japan: The power of tacit knowledge. The International Handbook of Innovation.

Nonaka, I, Toyama, R. (2007). Strategic management as distributed practical wisdom (phronesis). Industrial and Corporate Change. 16(3): 371-394.

Nonaka, I. Krogh, G.V. (2009). Tacit knowledge and knowledge conversion: controversy and advancement in organizational knowledge creation theory. Organization Science. 20(3):635-652.

OECD (2021, Tem.2) http:/ / oecd.org/sti/inno/406367101.pdf

Plessis. M.D. (2005). Drivers of knowledge management in the corporate environment. International Journal of Information Management. 25:193-202. 
Rose, J.F., Hawryszkiewycz, I. \& Kang, K. (2014). When and how to facilitate the introduction of new knowledge processes in organisations. VINE: The journal of information and knowledge management systems. 44(2): 210-227.

Quaddus. M., Xu. J. (2005). Adoption and diffusion of knowledge management systems: field studies of factors and variables. Knowledge-Based Systems.18:107-115.

Rai, R.K. (2011). Knowledge management and organizational culture: a theoretical integrative framework. Journal of Knowledge Management. 15(5):779-801.

Richtnér, A., Åhlström, P. \& Goffin, K. (2014). “Squeezing R\&D”: a study of organizational slack and knowledge creation in NPD, using the SECI model. J. Prod Innov Manag. 31(6). 1268-1290.

Sabri. H. (2005). Knowledge management in its context: adapting structure to a knowledge creating culture. IIJCM. 15(2):113-128.

Seidler-de Alwis, R, Hartmann, E. (2008). The use of tacit knowledge within innovative companies: knowledge management in innovative enterprises. Journal of Knowledge Management. 12(1):133147.

Serino, L., Papa, A., Campanella, F. \& Di Giola, L. (2020). The sourcing for collaborative knowledge translation in distributed R\&D processes: a cross-regional study. Management Decision. 58(9):20272048.

Sharp, D. (2003). Knowledge management today: challenges and opportunities. Information Systems Management. 20(2): 32-37.

Shuhuai, R., Xingjun, S., Haiqing, L. \& Jialin, C. (2009). From information commons to knowledge commons: Building a collaborative knowledge sharing environment for innovative communities. The Electronic Library. 27(2): 247-257.

Sigala, M., Chalkiti, K. (2014). Investigating the exploitation of web 2.0 for knowledge management in the Greek tourism industry: An utilisation-importance analysis. Computers in Human Behavior. 30:800-812.

Singh, B., Gautam, S. (2016). Hybrid spiral model to improve software quality using knowledge management. International Journal of Performability Engineering. 12(4):341-352.

Spraggon, M., Bodolica, V. (2008). Knowledge creation processes in small innovative hi-tech firms. Management Research News. 31(11): 879-894.

Tian, J., Nakamori, Y. \& Wierzbicki, A.P. (2009). Knowledge management and knowledge creation in academia: a study based on surveys in a Japanese research university. Journal of Knowledge Management. 13(2):76-92.

Turner, K.Y., Makhija, M.V. (2006). The role of organizational controls in managing knowledge. Academy of Management Review. 31(1):197-217.

Tutorials Point (2021, Tem.8) https://www.tutorialspoint.com/knowledge_management/knowledge_management_models.ht $\mathrm{m}$

Vaccaro. A., Parente, R.\& Veloso, F.M. (2009). Knowledge management tools, inter-organizational relationships, innovation and firm performance. Technological Forecasting \& Social Change.77:10761089.

Wu, Y., Senoo, D. \& Magnier-Watanabe, R. (2010). Diagnosis for organizational knowledge creation: an ontological shift SECI model. Journal of Knowledge Management. 14(1):791-810. 